\title{
Efficient microorganisms with probiotic effect, an alternative in swine health
}

\begin{abstract}
Use of microorganisms with probiotic capacity nowadays tends to be established in different systems of animal production throughout the world. The improvement in bioproductive behaviour when using probiotics in animal production depends not only on the production stage, but also on the selection of the strains used and the method of administration. Because the demand of international markets are products (meat, milk and eggs) healthy and that these do not directly or indirectly affect the health of man when consumed. In this review, we summarize some positive effects of microorganisms with probiotic capacity in the different categories of pigs at the production level. Bacteria and yeasts with probiotic effect in pigs are beneficial for health and productive indicators; the use of these bioproducts in the future could be promising for the benefit of human and animal health.
\end{abstract}

Keywords: animal health, lactic acid bacteria, yeasts

\section{Introduction}

The gastrointestinal tract system (GIT) hosts a large number of beneficial or harmful microorganisms (bacteria, yeasts, protozoa, among others) that fulfill various functions. ${ }^{1-3}$ The beneficial microorganisms have the ability to: a) strengthen the natural microbiota, ${ }^{1,4}$ b) inhibit the growth of pathogens, ${ }^{4}$ c) improve the absorption of nutrients ${ }^{5}$ and d) regenerate the atrophied microvilas. ${ }^{4,7}$ Unfortunately, the ability of the natural microbiota to fight intestinal pathogenic infections is not always effective., ${ }^{1,7,9}$ However, there are reports that the use of mixed cultures obtained from lactic acid bacteria (LAB) and probiotic yeasts help improve the health of the host. ${ }^{3,5,8}$ Since the end of the last century, the use of chemotherapeutics in animal health was considered a threat by many scientists, because most of these drugs used belong to drugs in man. ${ }^{1}$ Studies show that the use of probiotics in animals reduces the concentration of pathogens in animals, also decreases microbial resistance, because some bacteria can respond to other types of microbial species through plasmids $\mathrm{R}$ (fragment of genetic material) smaller than the chromosomes., ${ }^{3,9}$ Where they replicate autonomously in the cytoplasm of the cell and can cause a problem to human health. ${ }^{11}$ Therefore, some countries that are aware of these problems have increased the elimination of medicines as food additives, as is the case of antibiotics that promote growth, especially in the production of pigs and poultry, the main ones animal protein species. ${ }^{5,6,11}$ This situation has promoted important efforts in the search for alternatives to antibiotics, which fulfill similar functions in the animal's health and do not directly or indirectly affect human health. ${ }^{1,3,6}$ One of the alternatives with better results is the use of efficient microorganisms with probiotic capacity that can improve the resistance of animals to pathogenic bacteria and improve health.

\section{Discussion}

The microorganisms with greater probiotic capacity used in monogastric animals (pigs, birds, rabbits, horses, among others) are yeasts (Saccharomyces spp., S. boulardii, S. sabouraud, S. ovarum, Kluyveromyces spp., K. fragilis spp. K. fragilis L-4 UCLV, Candida utilis among others) and the bacteria (Lactobacillus spp., $L$. acidophilus, L. fermentum, L. rhamnosus, L. casei, L. bulgariccus. Enterococcus spp., Pediococcus spp., Bacillus spp., B. subtilis, B. licheniformis, Streptococos spp. S. thermophilus among others) the
Volume 4 Issue I - 2019

\author{
José E Miranda Yuquilema \\ Instituto Nacional de Biodiversidad, Quito, Ecuador
}

Correspondence: José E Miranda Yuquilema, Instituto Nacional de Biodiversidad, Quito, Ecuador,

Email efra_miranda@outlook.com

Received: February 19, 2019| Published: March 01, 2019 great majority of these organisms exert the probiotic function in the different portions of the GIT that houses an abundant and very diverse microbial population. ${ }^{1,3,4,8}$ Studies show that oral administration of microorganisms with probiotic capacity has shown beneficial effects for the health of pigs in different categories (Table 1), several small and large experiments in a high-performance commercial environment, the use of beneficial organisms in substitution of antibiotics (Neomycin, Oxytetracycline, Tylosin, among others) to treat some diarrheal disorders caused by different pathogens. ${ }^{9,11,12} \mathrm{~A}$ growing interest in the use of microorganisms with probiotic capacity is to reduce the digestive disorders of pigs caused by Escherichia coli or Salmonella spp. It has been shown that certain strains of $L$. acidophilus, L. bulgaricus, B. subtilis decrease the number of $E$. coli in piglet faeces or in vitro in stool suspensions and also appear to reduce the development of enteric Salmonella. ${ }^{5,6,9}$ The use of probiotics in swine production would represent a very practical strategy to reduce the proliferation of pathogens in the intestinal environment, therefore, the risk of infections in animal health. ${ }^{1,11,12}$ It has been shown that the use of mixed cultures (bacteria and yeast) in swine production improves diarrheal disorders, they could also offer the possibility of increasing bioproductive parameters. Probiotics obtained from Lactobacillus spp., Bifidobacterium spp., Enterococcus spp., Bacillus spp. generally act in the small intestine and limit the risk of colonizing pathogens. ${ }^{6,8}$ On the other hand, the use of live yeasts in animal feed acts from the moment of introduction. ${ }^{1,3}$ It has also been seen that the use of probiotic biopreparations in pregnant sows has improved the health of neonatal pigs. ${ }^{2}$ In addition, there are reports showing that the use of probiotics containing $S$. boulardii and $S$. cerevisiae in the diet of piglets after weaning improves nutrient uptake., ${ }^{3,10}$ Other studies carried out with yeast and lactic acid bacteria increase the early restoration of thinning of the intestinal mucosa that usually occurs at weaning and possibly improve local resistance to pathogens in the intestine. ${ }^{3,5,9}$ Probiotic regulate IgA levels at the intestinal level, a significant reduction of $E$. coli enterotoxinogenic has also been observed with the use of $S$. boulardii or $P$. acidilactici in piglets. ${ }^{5,6,8}$ In addition, similar findings have been reported on the modulation of IgA development, together with a decrease in ileal prevalence, with the use of L. sobrius, L. bulgariccus, $S$. thermophilus. ${ }^{1,8,11,12}$ In pigs for fattening, the productive performance, health and quality of the carcass have been improved. 
Table I Microorganisms with probiotic effects on the health of pigs in the different productive categories

\begin{tabular}{|c|c|c|c|}
\hline Categories & Beneficial microorganisms & Effects & Reference \\
\hline \multirow[t]{3}{*}{ Newborn } & $\begin{array}{l}\text { Lactobacillus spp., L. acidophulus, S. thermophilus, B. subtilis, S. } \\
\text { thermophilus, S. saccharomyces. K. fragilis L-4 uclv }\end{array}$ & Diarrhea reduction * & $1,4,7$ \\
\hline & & Death reduction $* *$ & \\
\hline & & Improves the immune system $* * *$ & \\
\hline Pre-weaning & $\begin{array}{l}\text { Lactobacillus spp., L. acidophulus, S. thermophilus, B. subtilis, S. } \\
\text { thermophilus, S. saccharomyces. K. fragilis L-4 uclv }\end{array}$ & $*, * *, * * *$ & $2,5,8$ \\
\hline \multirow[t]{3}{*}{ Post-weaning } & $\begin{array}{l}\text { Lactobacillus spp., L. acidophulus, S. thermophilus, B. subtilis, } S . \\
\text { thermophilus, S. saccharomyces. K. fragilis L-4 uclv, S. boulardii, P. } \\
\text { acidilactici }\end{array}$ & $*, * *, * * *$ & $1,3,4,5,10$ \\
\hline & & Regenerate atrophied microvils & \\
\hline & & Regulación de IgA & \\
\hline \multirow[t]{3}{*}{ Fattened pigs } & $\begin{array}{l}\text { Lactobacillus spp., L. acidophulus, S. thermophilus, B. subtilis, } S . \\
\text { thermophilus, S. saccharomyces. K. fragilis L-4 uclv }\end{array}$ & $*, * *, * * *$ & 1,4 \\
\hline & & Regulates the hemato-chemical levels & \\
\hline & & Improves the quality of the Chanel & \\
\hline \multirow[t]{2}{*}{ Gestation } & $\begin{array}{l}\text { Lactobacillus spp., L. acidophulus, S. thermophilus, B. subtilis, } S . \\
\text { thermophilus, S. saccharomyces. K. fragilis L-4 uclv }\end{array}$ & Regulates the hemato-chemical levels & $1,8,10,12$ \\
\hline & & Improves reproductive behavior & \\
\hline
\end{tabular}

\section{Conclusion}

The microorganisms with probiotic capacity in the different categories of pigs benefit positively and in the future would be promising for the benefit of the animal's health. Several investigations show that the use of probiotics can positively balance the natural microbiota, therefore, improve the state of animal health. However, a design and an adequate dose for the animals have not yet been established. It is important to select specific strains on a scientific basis and follow their behavior under strict control in vitro studies.

\section{Acknowledgments}

None.

\section{Conflicts of interest}

Authors declare that there is no conflicts of interest.

\section{References}

1. Yadav S Bajagai, Athol V Klieve, Peter J Dart, et al. Editor Harinder P.S Makkar FAO. Probiotics in animal nutrition - Production, impact and regulation by. FAO Animal Production and Health. 2016.

2. Miranda JE, Marin A, Lazo L, et al. Repercussion of lactic bacteria and yeasts on the productive performance and health of piglets. Rev Inv Vet Perú. 2018;29(4):1203-1212.

3. Davis M, Parrott T, Brown D, et al. Effect of a Bacillus based directfed microbial feed supplement on growth performance and pen cleaning characteristics of growing-finishing pigs. J Ani Sc. 2008;86(6):14591467.

4. Miranda JE, Marin A, García Y. Repercussion of microbial additive on the productive, Zoometric and diarrheal incidences of piglets. $J M V Z$, Córdoba. 2018;23(2):6617-6627.
5. Asli M, Hosseini S, Lotfollahian H, et al. Effect of probiotic, yeast, vitamin $\mathrm{E}$ and vitamin $\mathrm{C}$ supplements on performance and immune response of laying hen during high environmental temperature. Int $J$ Poult Sc. 2007;6(12):895-900.

6. Miranda JE, Marin A, Marrero L, et al. Efecto de biopreparados sobre el comportamiento bioproductivo de cerdas y sus crías. Rev Cient FVCLUZ. 2018;XXVIII(4):298-305.

7. Hyronimus B, Le Marrec C, Sassi AH. et al. Acid and bile tolerance of spore-forming lactic acid bacteria. Int J Food Microb. 2000;61(2):193197.

8. Miranda JE, Marin A, Oliva H, et al. Influence of a microbial additive on the productive behaviour of pregnant sows, as well as, hematochemical and diarrheal incidence in their offspring. Trop Subtrop Agroecosyt. 2018;21(2018):39-45.

9. Alexopoulos C, Georgoulakis I, Tzivara A, et al. Field evaluation of the efficacy of a probiotic containing Bacillus licheniformis and Bacillus subtilis spores, on the health status and performance of sows and their litters. J An Phys Ani Nutr. 2004;88(11-12):381-392.

10. Miranda JE, Marin A, Marrero L, et al. Evaluation of hemochemical changes in the blood of piglets supplemented with two microbial preparations. Cuban J Agr Sci. 2018;52(1):57-65.

11. Abdel M, Abd S, Hassanein K. The effects of probiotic, probiotic and symbiotic supplementation on intestinal microbial ecology and histomorphology of broiler chickens. Int J Agr Vet M Sc. 2012;6(4):277289.

12. Miranda JE, Marín A, González M. El comportamiento bioproductivo de cerdas reproductoras y su descendencia alimentadas con aditivo probiótico. Rev Cienc Agr. 2018;35(1):69-81. 